\title{
Improvement of ENEA laser-induced fluorescence prototypes: an intercalibration between a hyperspectral and a multispectral scanning system
}

\author{
Maria Federica Caso ${ }^{1}$, Luisa Caneve ${ }^{1}$, Valeria Spizzichino ${ }^{1}$ \\ ${ }^{1}$ ENEA - Italian National Agency for New Technologies, Energy and Sustainable Economic Development - Via Enrico Fermi 45, \\ 00044 Frascati, Rome, Italy
}

\begin{abstract}
Laser-induced fluorescence (LIF) is a well-recognised spectroscopic technique used in cultural heritage for non-destructive surface chemical analysis. It is particularly suitable for in situ analysis of delicate items such as artworks because it does not require any sample preparation or contact and can be used at a distance in situations where only optical access is available. Recently, ENEA has developed two LIF prototypes with multispectral (Forlab) and hyperspectral (Lifart) scanning systems that each return different types of results, making them necessary for and dependent on each other. Forlab's motorised optics enable the rapid acquisition of fluorescence maps and images of large surfaces in specific spectral wavelengths, while Lifart returns complete fluorescence spectra, providing the complete spectral information of an object. In this paper, the intercalibration of the two systems is reported together with a data analysis of the calibration samples and a software that automatically corrects imaging data, taking Forlab's filter passband and optical efficiencies into account in order to make these two configurations as easy to compare as possible. The new correcting algorithm is also tested on LIF measurements carried out on an Egyptian casket and sarcophagus, obtaining higher quality fluorescence images.
\end{abstract}

Section: RESEARCH PAPER

Keywords: Laser-induced fluorescence (LIF); LIF prototypes; intercalibration; cultural heritage analysis; sarcophagus LIF analysis

Citation: Maria Federica Caso, Luisa Caneve, Valeria Spizzichino, Improvement of ENEA laser-induced fluorescence prototypes: an intercalibration between a hyperspectral and a multispectral scanning system, Acta IMEKO, vol. 10, no. 1, article 10, March 2021, identifier: IMEKO-ACTA-10 (2021)-01-10

Editor: Eulalia Balestrieri, University of Sannio, Italy

Received April 22, 2020; In final form October 13, 2020; Published March 2021

Copyright: This is an open-access article distributed under the terms of the Creative Commons Attribution 3.0 License, which permits unrestricted use, distribution, and reproduction in any medium, provided the original author and source are credited.

Funding: ADAMO regional project within DTC (Technological District for Cultural Heritage) Lazio Det.reg. G08622

Corresponding author: Maria Federica Caso, e-mail: mariafederica.caso@enea.it

\section{INTRODUCTION}

Over the last decades, spectral imaging technology, which was previously restricted to astrophysics, remote sensing and military applications [1], has been employed in cultural heritage, thanks to the development of infrared reflectography in the study of paintings [2], [3]. Increases in the number of spectral bands due to improved imaging spectrometers and technical advancements have led to the emergence of hyperspectral imaging [4]. These spectral imaging systems, which are able to collect both spectral and spatial information, are non-invasive, and, for this reason, are particularly suitable for the diagnostic and digital imaging of artworks [5].

Laser-induced fluorescence (LIF) is a spectroscopic technique that has been widely used over the last 40 years for many scientific activities, such as conducting combustion diagnostics
[6], [7], probing energy transfer processes in molecules and atoms [8], identifying gastrointestinal tumours [9]-[11] and melanoma skin cancers [12] and characterising cardiovascular tissue [13], [14]. LIF spectroscopy detects the UV-vis radiations emitted by luminescent molecules on the target surface caused by allowed electronic transitions stimulated by UV laser. The emission spectrum can provide a large amount of both qualitative and quantitative information about the chemistry and molecular structure of a sample [15].

Like many other laser-based diagnostic instruments [16], LIF spectroscopy has been widely used in the cultural heritage field [17]-[18]. Most biological and organic materials common to the field of cultural heritage [20] absorb deep UV, corresponding to their first electronic state, and, through fluorescence and/or phosphorescence, emit at longer wavelengths, generally greater than $280 \mathrm{~nm}$ [21]. One of the advantages of fluorescence and 
Table 1. Features of Forlab filters.

\begin{tabular}{cc}
\hline Forlab filter wavelength & \multicolumn{2}{c}{ Transmission band } \\
\hline $290 \mathrm{~nm}$ & $T_{\text {avg }}>75 \% \quad 277.5-302.5 \mathrm{~nm}$ \\
$315 \mathrm{~nm}$ & $\mathrm{~T}_{\text {avg }}>75 \% \quad 307.5-322.5 \mathrm{~nm}$ \\
$340 \mathrm{~nm}$ & $\mathrm{~T}_{\text {avg }}>75 \% \quad 327-353 \mathrm{~nm}$ \\
$376 \mathrm{~nm}$ & $\mathrm{~T}_{\text {avg }}>95 \% \quad 366-386 \mathrm{~nm}$ \\
$415 \mathrm{~nm}$ & $\mathrm{~T}_{\text {avg }}>90 \% \quad 410-420 \mathrm{~nm}$ \\
$445 \mathrm{~nm}$ & $T_{\text {avg }}>93 \% \quad 435-455 \mathrm{~nm}$ \\
$480 \mathrm{~nm}$ & $\mathrm{~T}_{\text {avg }}>92 \% \quad 471.5-488.5 \mathrm{~nm}$ \\
$530 \mathrm{~nm}$ & $\mathrm{~T}_{\text {avg }}>93 \% \quad 521-539 \mathrm{~nm}$ \\
\hline
\end{tabular}

phosphorescence is that their spectra are generally independent of the excitation wavelength [22]-[23]. This technique is nondestructive and non-invasive, does not cause modifications or degradations of the chemical structure of targets and does not need any sample preparation. For this reason, it is particularly recommended for fragile and delicate artworks [25]. Furthermore, LIF instruments do not require contact and can be used at a distance or in situations in which only optical access is available while maintaining their high sensitivity. Transportable instruments can be easily designed for in situ analysis, providing results in real time [26].

Recently, ENEA has developed LIF prototypes with hyperspectral (Lifart) [27] and multispectral (Forlab) [28] scanning systems that are capable of both fluorescence and reflectance imaging. They return different types of spatial and spectral information, making them necessary for and dependent on each other. In particular, Forlab was designed to permit the rapid acquisition of fluorescence maps of large surfaces (up to $100 \mathrm{~m}^{2}$ ) in specific spectral wavelengths, allowing for faster acquisitions and providing results in real time. Furthermore, a custom software was developed for this system for the automatic recognition of specific classes of materials. Conversely, Lifart returns complete fluorescence spectra, providing the complete spectral information of an object.

The two LIF systems described here are innovative prototypes, specifically designed for remote (entailing a distance up to some tens of meters) cultural heritage investigations. They possess complementary features for the fast and accurate characterisation of both large and small artworks thanks to their different configurations. These differences, however, have hampered the combined use of the two instruments, which has until now been quite laborious.

To overcome this point, this work investigates the intercalibration of the two instruments, taking into account Forlab's filter passband and optical efficiencies. This intercalibration makes the data registered by the two instruments as easy to compare as possible.

The numerical elaboration so obtained represents a significant step forward, creating an innovative tool for the rapid early diagnosis of large surfaces. In fact, the intercalibration described here makes it possible to combine the two ENEA prototypes, which dramatically improves the presentation and interpretation of results, thanks to the overlap and comparison of data and the expected increased readability of spectra.

\section{INSTRUMENTATION}

This paper focuses on two specific instruments developed by ENEA Diagnostic and Metrology Laboratory: the hyperspectral LIF scanning system (Lifart) and the multispectral LIF scanning

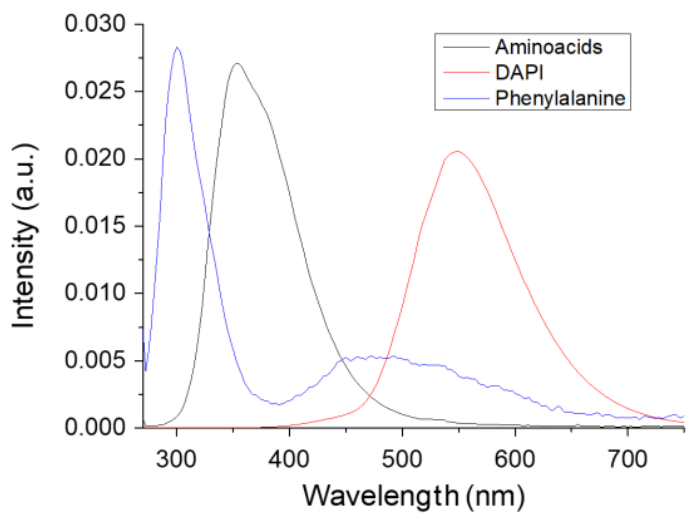

Figure 1. Fluorescence spectra of reference solutions.

system (Forlab), whose detailed technical features have already been described [27], [28]. Briefly, Lifart can be used at a distance of up to $10 \mathrm{~m}$ from the target via a diode-pumped solid state laser emitting at $266 \mathrm{~nm}$ in the UV. A coaxial optical design is used to transmit the exciting radiation and receive the fluorescence signals from the investigated target. Point scanning is accomplished by manipulating the last mirror using two highly accurate rotation servo motors. The practical scanning range is limited by the mounting assembly to approximately $\pm 45^{\circ}$ in both the horizontal and vertical axes. The fluorescence radiation is focused into a fibre-optic cable linked to a compact QE-Pro spectrometer from Ocean Optics, allowing for hyperspectral imaging in the range of $250-900 \mathrm{~nm}$ with a $2.5 \mathrm{~nm}$ bandwidth.

Forlab is a multispectral system that enables the rapid collection of large images on several different spectra. The system is based on the use of motorised laser delivery optics to scan the whole surface to be analysed with a UV laser (excimer $\mathrm{KrF}$ laser at $248 \mathrm{~nm}$ ). The collecting subsystem, which is connected to an ICCD camera (Andor iStar) with a large field of view, is fixed. The laser source is characterised by a high pulse repetition rate (up to $500 \mathrm{~Hz}$ ), which lowers the acquisition time. A filter wheel is mounted in front of the ICCD in order to detect fluorescence images at 8 preselected spectral bands (Table 1. Features of Forlab filters. Table 1).

Both systems are able to acquire fluorescence and reflectance spectra with the laser switched on or off, respectively. Fluorescence data can be processed to obtain fluorescence and false colour images for material mapping. Active reflectance measurements are based on elastic backscattering of the incident light collected from the analysed surface in daylight or under a specific white light source.

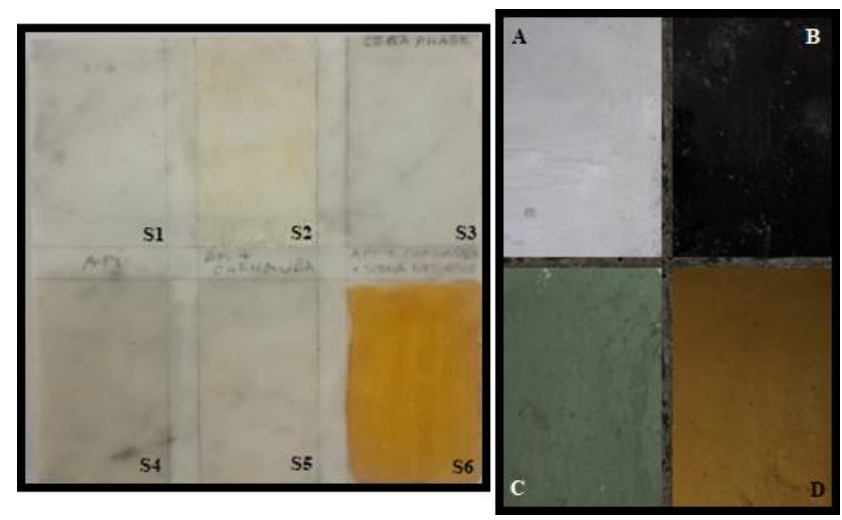

Figure 2. Reference samples. Left: marble tile. Right: earthenware tile. 


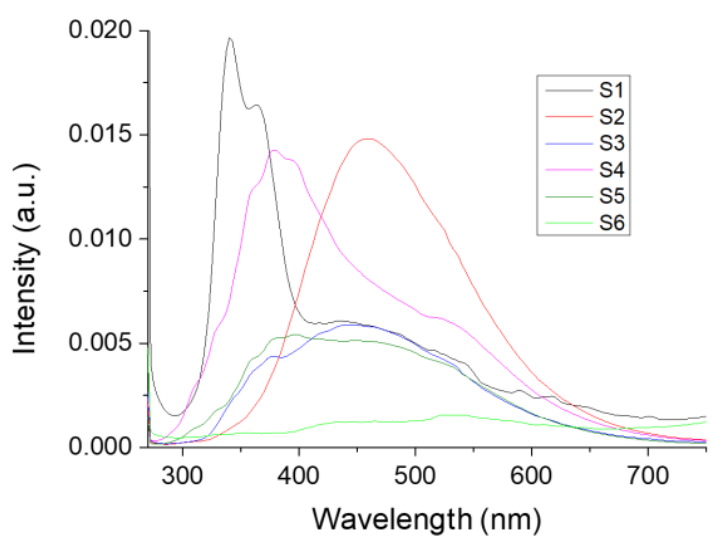

Figure 3. Fluorescence spectra of the six sections of marble tile.

\section{MATERIALS}

Several different materials, including laboratory samples and real artworks, were used to calibrate and test the instruments in order to evaluate the correction algorithm. For the intercalibration of the two instruments, materials characterised by known fluorescence spectra covering the entire range between 270 and $700 \mathrm{~nm}$ were selected. In particular, solutions of phenylalanine $(0.1 \mathrm{M}), 4$ ', 6-diamidino-2-phenylindole (DAPI, 5 $\mathrm{mg} / \mathrm{ml}$ ) and a mix of amino acids (tyrosine $0.017 \mathrm{M}$, tryptophan $0.018 \mathrm{M}$ and phenylalanine $0.1 \mathrm{M}$ ), which are also responsible for protein fluorescence in organic media in paintings [29], were prepared, and their fluorescence spectra excited at $266 \mathrm{~nm}$ are presented in Figure 1.

Additionally, a reference model (Figure 2, left) simulating some real case studies was selected to mimic a sample that might be encountered during a field campaign. The sample was a Carrara marble tile divided into six sections:

S1) Marble;

S2) Carnauba wax (vegetable wax);

S3) Phase wax (industrial wax);

S4) Beeswax;

S5) Beeswax and carnauba wax mixture;

S6) Beeswax and carnauba wax mixed with sienna pigment.

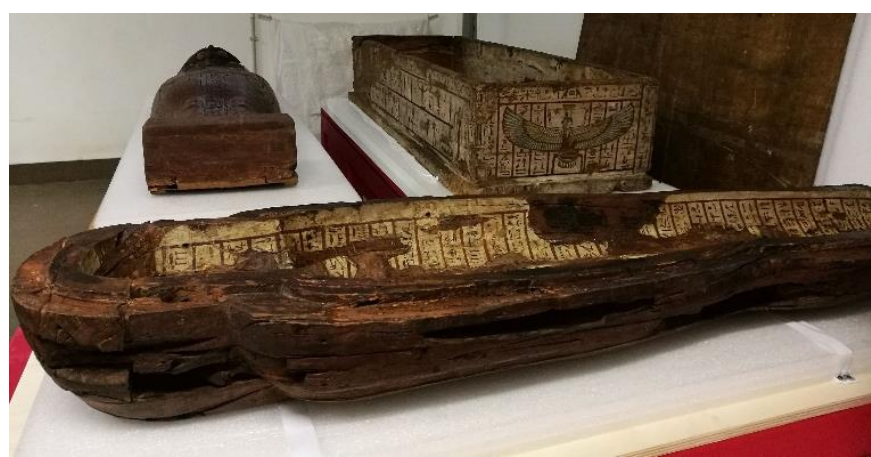

Figure 4. Egyptian casket and sarcophagus.

These materials were chosen because their fluorescence spectra cover the whole wavelength range of interest. Moreover, these materials have often been used as coatings in sculpture and architecture since antiquity, and sienna and ochre were frequently applied to give a chiaroscuro effect to artworks. In Figure 3, the fluorescence spectra of the six sections obtained with an excitation at $266 \mathrm{~nm}$ are presented.

Another sample prepared in the laboratory, an earthenware tile (Figure 2, right), was used to test the obtained intercalibration. Using buon fresco or mezzo fresco techniques, this sample was treated with a lime-pozzolan mortar and a pigment and then covered with a modern surface coating. In particular, the four sections of the tile were composed of the following:

A) White lead and Rhodorsil RC-80;

B) Vine black and Rhodorsil RC-80;

C) Green earth and Paraloid B72;

D) Yellow ochre and Rhodorsil RC-80.

The calibration was also tested on a real ancient artwork. In particular, a previous study [30] on ancient Egyptian artworks was chosen to validate the calculous for a third material, wood. The analysis of the fluorescence spectra of the casket and sarcophagus of Peftjauyauyaset (XXVI din. -VII-VI sec. a.C.) from the Archaeological Museum of Milan (Figure 4) was chosen because of the discontinuity of the artwork's surface. The spectra
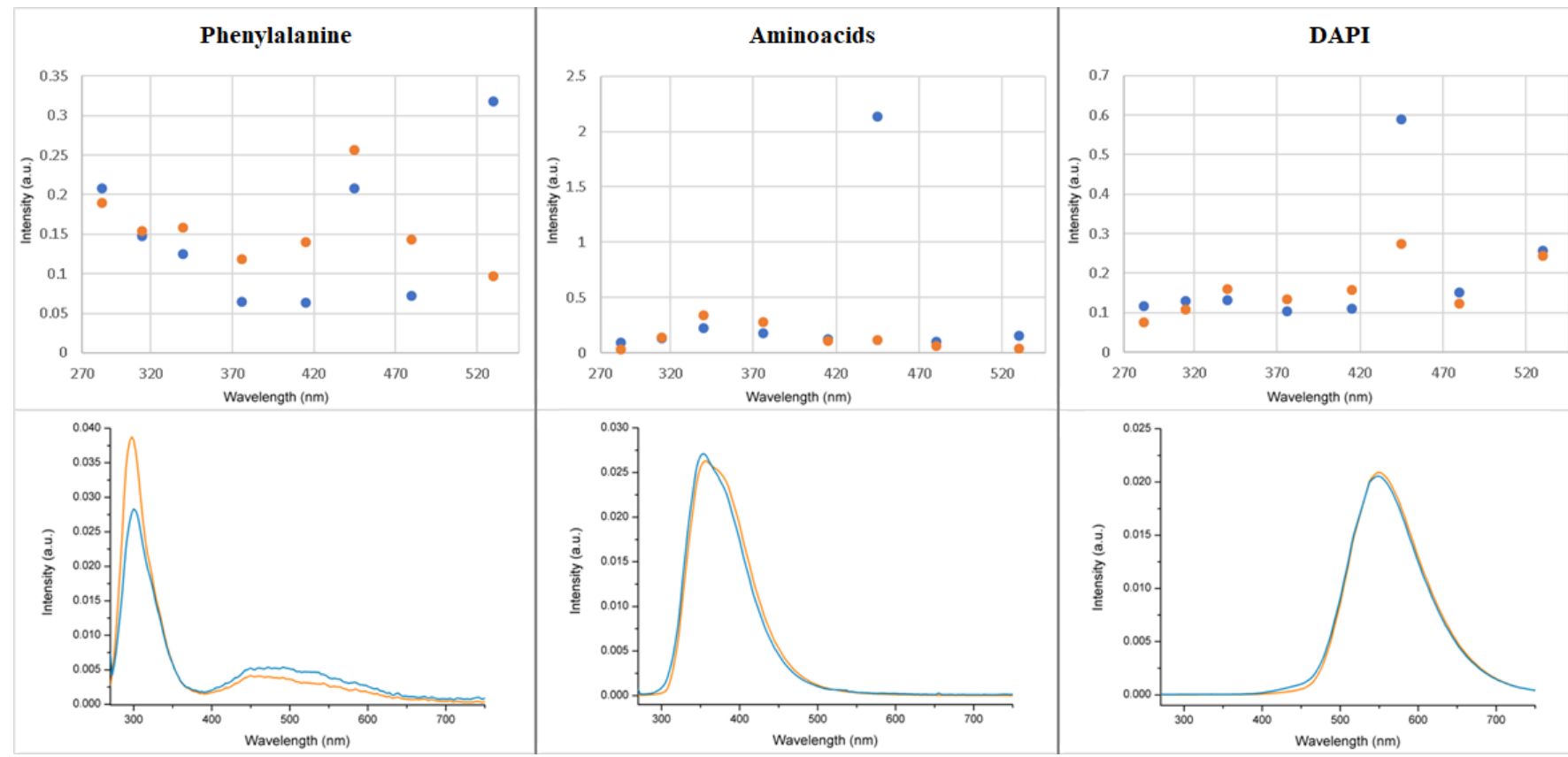

Figure 5. Measurements of reference solutions with Forlab (top) and Lifart (bottom) equipped with both lasers. Orange: KrF at $248 \mathrm{~nm}$; blue: Nd:YAG at 266 $\mathrm{nm}$. 
Table 2. Calibration ratios obtained from the reference solutions and sections S1, 2 and 4 of the tile. Only blue values were considered in calculations.

\begin{tabular}{|c|c|c|c|c|c|c|}
\hline Forlab filter wavelengths & Phenylalanine & Amino acids & DAPI & S1 & S2 & S4 \\
\hline $290 \mathrm{~nm}$ & 9.32 & 75.77 & 2459.86 & 71.79 & 150.25 & 39.52 \\
\hline $315 \mathrm{~nm}$ & 7.17 & 28.11 & 2664.24 & 49.09 & 165.13 & 24.51 \\
\hline $340 \mathrm{~nm}$ & 16.33 & 15.58 & 3709.70 & 19.41 & 117.02 & 36.74 \\
\hline $376 \mathrm{~nm}$ & 53.38 & 11.54 & 2013.75 & 12.88 & 62.79 & 22.12 \\
\hline $415 \mathrm{~nm}$ & 50.10 & 8.96 & 410.70 & 16.59 & 29.05 & 16.75 \\
\hline $445 \mathrm{~nm}$ & 53.38 & 21.88 & 299.98 & 22.86 & 21.84 & 21.71 \\
\hline $480 \mathrm{~nm}$ & 27.36 & 31.88 & 31.45 & 6.90 & 10.67 & 7.62 \\
\hline $530 \mathrm{~nm}$ & 20.83 & 63.52 & 13.24 & 9.30 & 15.79 & 6.35 \\
\hline
\end{tabular}

successfully revealed the presence of non-homogeneous materials applied in previous restoration actions. Moreover, the fully decorated surfaces provide an amplified chiaroscuro contrast that improves the image quality when the calibration is applied to the Forlab results.

\section{RESULTS AND DISCUSSION}

\subsection{System intercalibration}

The reference solutions and the marble tile described in Section 3 were utilised for the intercalibration.

Preliminary experiments involved measurements of the reference solutions only with both Lifart (whole spectra) and Forlab (8 filters at 290, 315, 340, 376, 415, 445, 480 and $530 \mathrm{~nm}$ ) equipped with either $\mathrm{KrF}$ emitting at $248 \mathrm{~nm}$ or $\mathrm{Nd}: \mathrm{YAG}$ emitting at $266 \mathrm{~nm}$ in order to assess the different contributions of the laser sources and optical systems to the acquisition of the signal. In the Forlab spectra, reported on the top half of Figure 5 , with the exclusion of the signal at $445 \mathrm{~nm}$ (probably due to a filter malfunctioning), the spectra present a fairly good correspondence when distinguished from the exciting source. This point will not be considered in further elaboration. Phenylalanine shows significant discrepancies in the region above $350 \mathrm{~nm}$ because of very low emissions in that region. Therefore, in this case, we only used signals in the region below $350 \mathrm{~nm}$ for the calibration.

A similarly good spectra correspondence was observed in the Lifart spectra shown in the bottom half of Figure 5. Major discrepancies in the spectra of phenylalanine were attributed to the high proximity of the laser source wavelength to that of the absorption of phenylalanine.

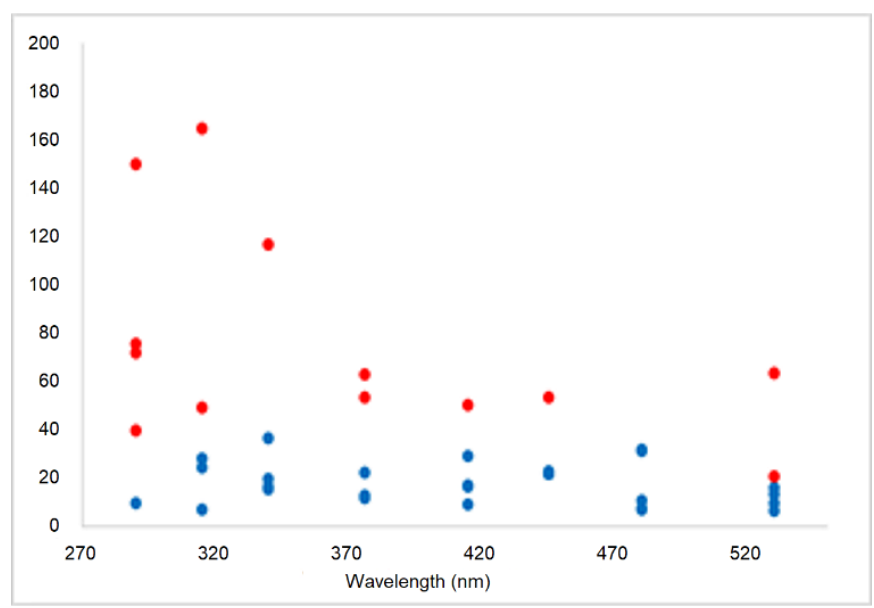

Figure 6. Calibration values: considered values in blue, excluded values in red.
Fluorescence analyses for the intercalibration were carried out with both Lifart and Forlab on drops of the reference solutions placed on an aluminium surface as well as on a small square in the centre of the sections of the marble tile, and Lifart and Forlab spectral data registered in this area were mediated.

The recorded data were processed to obtain intercalibration values that were as independent of the experimental measurement conditions as possible. First, the transmission bands of the Forlab filters (reported in Table 1) had to be considered. After this correction, both instruments' data were normalised with the integral across the whole range (the sum of the intensity values corresponding to the 8 filters for Forlab). Second, to compare Forlab and Lifart data, only spectral data from Lifart mediated within the passband of the filters used in Forlab were considered.

Sections 1, 2 and 4 of the marble tile were preferred due to the high reproducibility of their measurements and their higher fluorescence intensity with respect to the others. The Forlab and Lifart fluorescence data for the reference solutions and sections S1, 2 and 4 of the tile were divided, and the resulting quotients, called calibration ratios, are presented in Table 2 . The blue values in Table 2 were considered reliable because they had higher signal to noise ratios, as verifiable in Figure 1 and Figure 3. Therefore, these values were used to calculate the final ratios. Unfortunately, just one value was considered for filter 290 because only phenylalanine presented a peak in the $270-340 \mathrm{~nm}$ wavelength range.

A confirmation of this assessment is provided in Figure 6. The blue points indicate the highlighted blue values from Table 2 , and the red points indicate values that were not used in the calibration of the ratio calculous due to their distance from the blue points or their incoherence.

The final calibration ratios, which were utilised for the intercalibration, were obtained by mediating the highlighted blue values. They are presented with their corresponding standard deviations in Table 3.

Table 3. Calibration ratios for every Forlab filter.

\begin{tabular}{ccc}
\hline Forlab filter wavelengths & Calibration ratios & Standard deviation \\
\hline $290 \mathrm{~nm}$ & 9.32 & $/$ \\
$315 \mathrm{~nm}$ & 19.93 & 11.2 \\
$340 \mathrm{~nm}$ & 22.01 & 10.0 \\
$376 \mathrm{~nm}$ & 15.51 & 5.8 \\
$415 \mathrm{~nm}$ & 17.84 & 8.3 \\
$445 \mathrm{~nm}$ & 22.07 & 0.5 \\
$480 \mathrm{~nm}$ & 19.31 & 12.1 \\
$530 \mathrm{~nm}$ & 11.17 & 4.2 \\
\hline
\end{tabular}



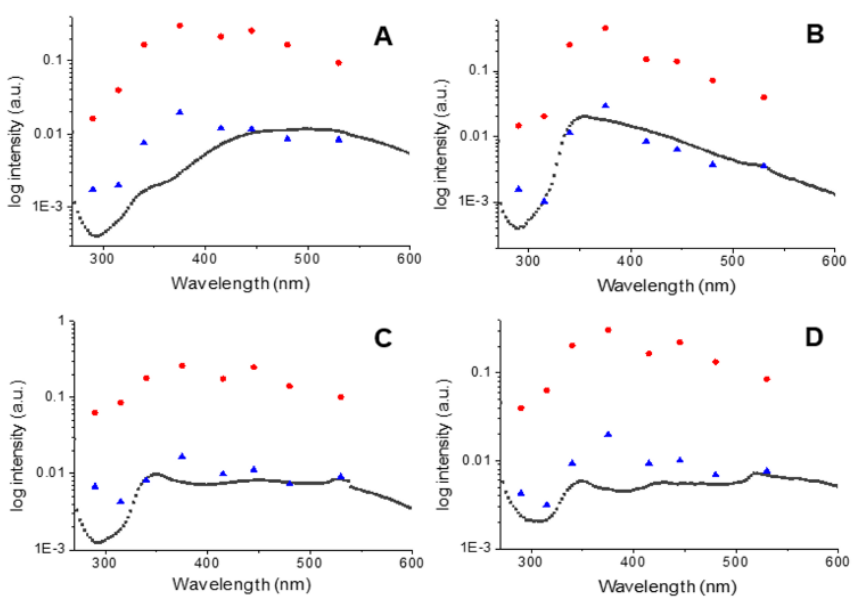

Figure 7. The earthenware tile fluorescence spectra. Black: Lifart fluorescence spectra; blue: Forlab values calibrated; red: Forlab values not calibrated. A-D refer to the four areas described in the materials section.

\subsection{Application of calibration ratios to a laboratory sample}

The calibration ratios were applied to the 4 sections of the earthenware tile described before. As in the previous tile, a small square in the centre of every section was selected, and the corresponding Lifart and Forlab spectral data of this area were averaged. The Forlab data before and after calibration were plotted with the Lifart spectra to highlight the fairly good correspondence of Lifart spectra and calibrated Forlab values (Figure 7). The calibrated values, although not perfectly matched with Lifart ones, presented the same shapes and trends in the peaks and bands.

\subsection{Application of calibration ratios to a real case}

The calibration ratios were applied to a previous study [30] of the Egyptian casket and sarcophagus described in Section 3.

The processed data confirmed the discontinuity of the surface materials and the identification of the modern coatings applied
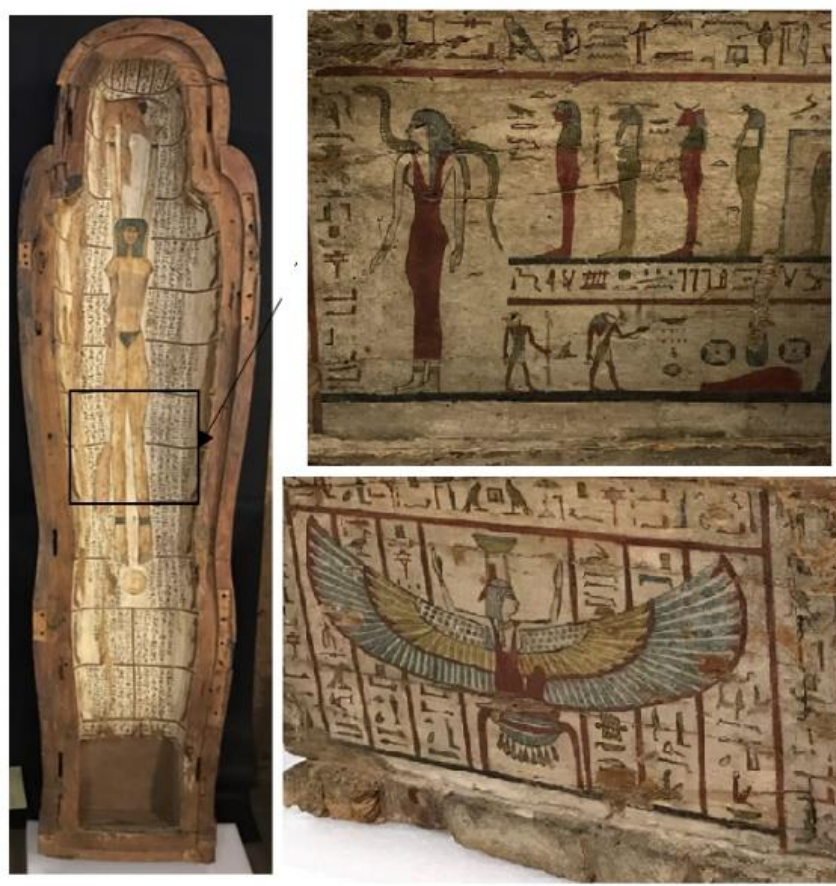

Figure 8. Upper valve of the sarcophagus, long and short side of the casket.

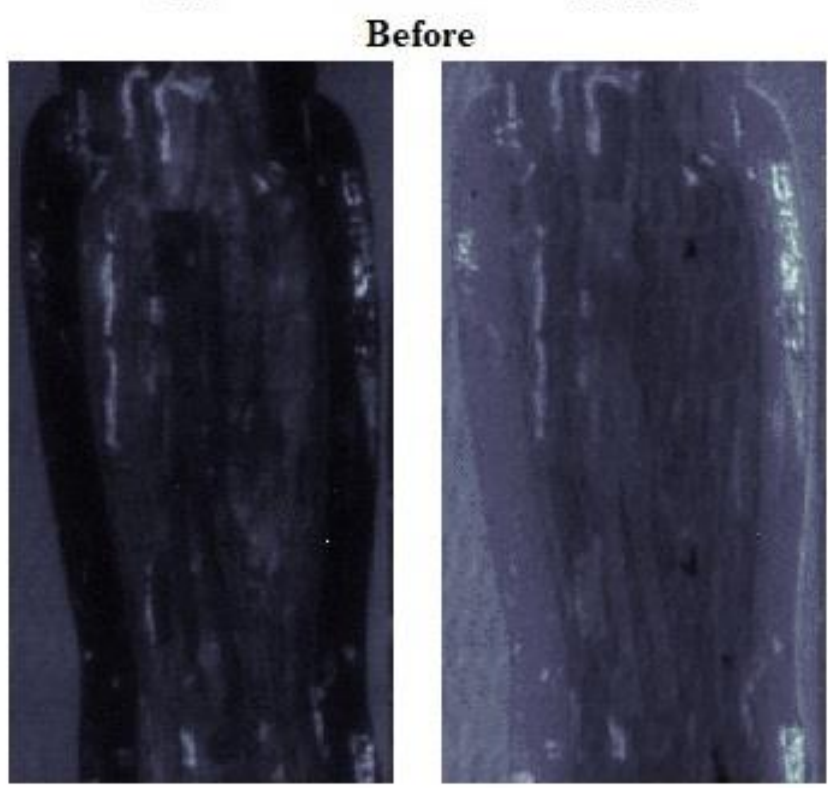

After
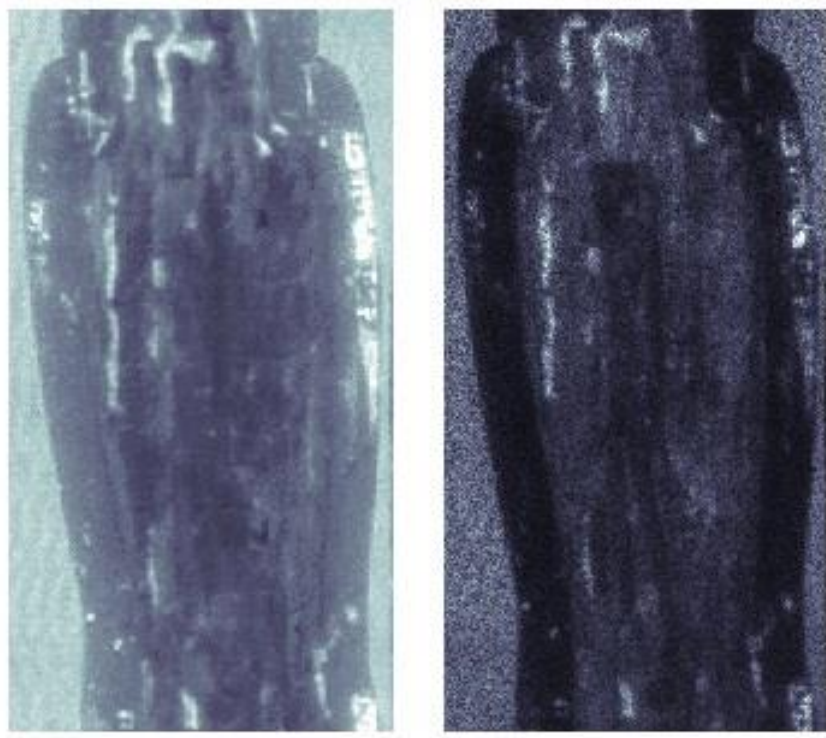

Figure 9. Forlab fluorescence ratios of the interior part of the upper valve of the sarcophagus.

in an undocumented restoration action. Forlab data provided evidence of some retouches not visible to the naked eye, and the application of Lifart on these spots made it possible to identify zinc oxide, acrylic paint and more.

Very interesting results were obtained by the analysis of the external part of the casket and the interior part of the upper valve of the sarcophagus (Figure 8), where the presence of canvas under the paints and acrylic coating was revealed on the legs of the goddess Nut.

Forlab images at preselected wavelengths can be employed for the definition of signal ratios and the development of algorithms aimed at the identification of different substances. The application of calibration ratios to Forlab fluorescence ratios made it possible not only to obtain more luminosity, contrast and definition in the images (Figure 9) but also to emphasise the different treatments through the correction of the highlighted areas, making the data more reliable. The discontinuity of the surface materials was also evident on the long and short sides of 


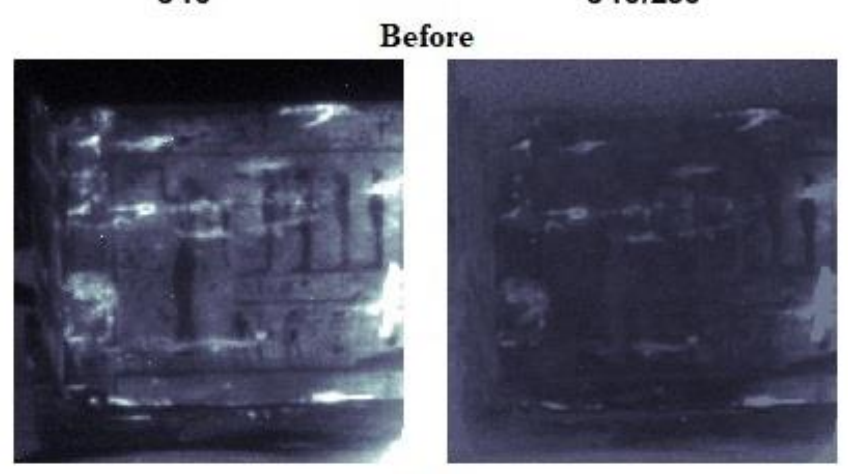

After
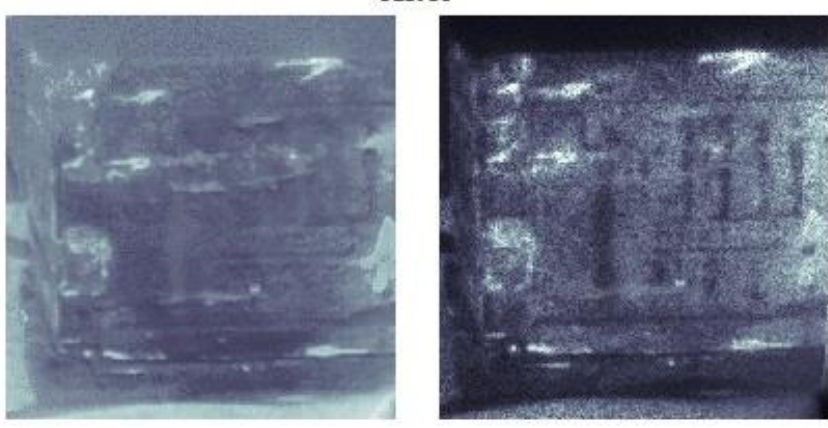

Figure 10. Forlab fluorescence ratios of the long side of the casket.

the casket (Figure 10 and Figure 11). In fact, the Forlab processed data, confirmed by Lifart analysis, showed the presence of acrylic consolidation material applied in several restorations over time.

The calibration ratios considerably improved the quality of the Forlab images (Figure 11), making some fissures and several restorations stand out in the casket, particularly near the winged goddess Nefti. Furthermore, a more precise localisation of materials and retouches was obtained by applying the calibration ratios to all of the Forlab measurements.

\section{CONCLUSIONS}

LIF spectroscopic technique is used widely in the field of cultural heritage because it allows easy access to valuable information without damaging the specimens. ENEA Diagnostic and Metrology Laboratory developed hyperspectral and a multispectral LIF scanning systems, whose intercalibration provided a correction tool for imaging data.

Some reference solutions and a Carrara marble tile treated with different coatings were employed to develop calibration ratios for the Forlab system. These ratios were then applied to the fluorescence spectra of an earthenware tile covered with pigments and modern protective paints. The obtained results, although still imperfect, proved very encouraging and provided higher quality Forlab images. Moreover, the availability of an intercalibration protocol is expected to provide access to extrapolated spectra from Forlab data.

\section{ACKNOWLEDGEMENT}

The authors would like to thank ADAMO regional project in the frame of DTC (Technological District for Cultural Heritage) Lazio Det.reg. G08622 and E. Antonelli and the Consorzio Croma laboratory for their collaboration and maximum availability for measurements.
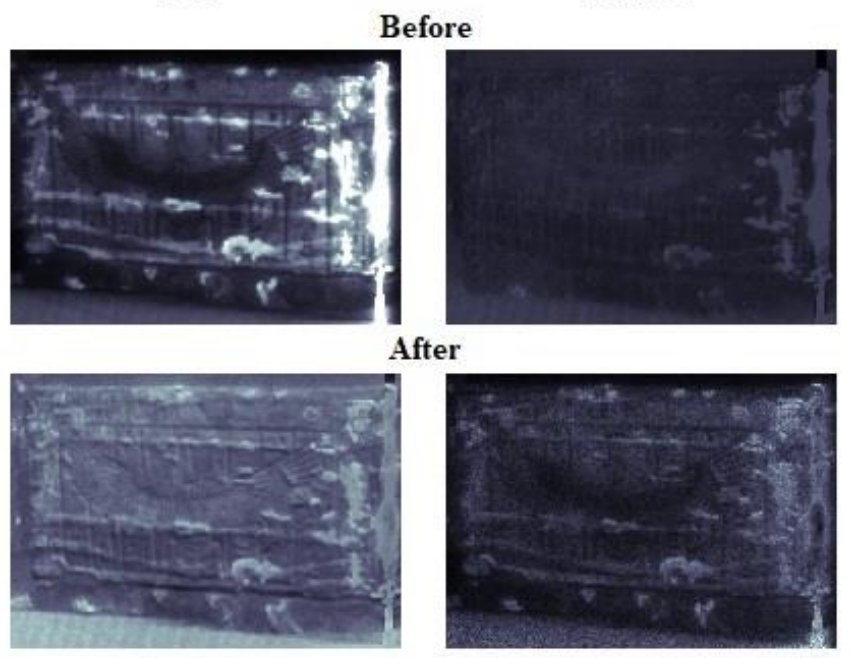

Figure 11. Forlab fluorescence ratios of the short side of the casket.

\section{REFERENCES}

[1] A. N. Rencz, R. A. Ryerson, Manual of Remote Sensing Vol. 3, Remote Sensing for the Earth Sciences, Wiley \& Sons, New York, 1999, ISBN 0471294055, 9780471294054.

[2] J. R. J. Van Asperende Boer, Examination by infrared radiation, PACT 13 (1986), pp. 109-130.

[3] A. Burmester, F. Bayerer, Towards improved infrared reflectograms, Studies in Conservation 38 (1993), pp. 145-154 DOI: $10.2307 / 1506376$

[4] D. C. Creagh, D. Bradley, Physical Techniques in the Study of Art, Archaeology and Cultural Heritage, Elsevier, Amsterdam, 2007, ISBN 0080548814, 9780080548814 .

[5] C. Fischer, I. Kakoulli, Multispectral and hyperspectral imaging technologies in conservation: current research and potential applications, Studies in Conservation 51:sup1 (2006), pp. 3-16. DOI: $10.1179 /$ sic.2006.51.Supplement-1.3

[6] J. W. Daily, Laser induced fluorescence spectroscopy in flames, Prog. Energy Combust. Sci. 23 (1997), pp. 133-199.

DOI: $10.1016 / \mathrm{S} 0360-1285(97) 00008-7$;

[7] D. R. Crosley, G. P. Smith, Laser-induced fluorescence spectroscopy for combustion diagnostics, Optical Engineering 22(5) (1983), pp. 545-553.

DOI: $10.1117 / 12.7973194$

[8] R. W. Solarz, J. A. Paisner, R. P. Lucht, Laser Spectroscopy and its Applications. Applications of Laser-Induced Fluorescence Spectroscopy for Combustion and Plasma Diagnostics, Routledge, New York, 1987, ISBN 9780203749104, pp. 620-673.

[9] L. P. Hariri, A. R. Tumlinson, D. G. Besselsen, U. Utzinger, E. W. Gerner, J. K. Barton, Endoscopic optical coherence tomography and laser-induced fluorescence spectroscopy in a murine colon cancer model, Lasers in Surgery and Medicine 38 (2006), pp. 305313.

DOI: $\underline{10.1002 / 1 \mathrm{sm} .20305}$

[10] R. M. Cothren, R. Richards-Kortum, M. V. Sivak, M. Fitzmaurice, R. P. Rava, G. A. Boyce, M. Doxtader, R. Blackman, T. B. Ivanc, G. B. Hayes, M. S. Feld, R. E. Petras, Gastrointestinal tissue diagnosis by laser induced fluorescence spectroscopy at endoscopy, Gastrointestinal Endoscopy 36(2) (1990), pp. 105-111. DOI: $10.1016 /$ S0016-5107(90)70961-3

[11] C. R. Kapadia, F. W. Cutruzzola, K. M. O’Brien, M. L. Stetz, R. Enriquez, L. I. Deckelbaum, Laser-induced fluorescence spectroscopy of human colonic mucosa, Gastroenterology 99(1) (1990), pp. 150-157.

DOI: $\underline{10.1016 / 0016-5085(90) 91242-X}$ 
[12] M. Panjehpour, C. E. Julius, M. N. Phan, T. Vo-Dinh, S. Overholt, Laser-induced fluorescence spectroscopy for in vivo diagnosis of non-melanoma skin cancers, Lasers in Surgery and Medicine 31 (2002), pp. 367-373. DOI: $10.1002 / \mathrm{lsm} .10125$

[13] A. M. K. Nilsson, D. Heinrich, J. Olajos, S. Andersson-Engels, Near infrared diffuse reflection and laser-induced fluorescence spectroscopy for myocardial tissue characterisation, Spectrochimica Acta Part A 53(11) (1997), pp. 1901-1912. DOI: $10.1016 /$ S1386-1425(97)00106-6

[14] J. J. Baraga, R. P. Rava, P. Taroni, C. Kittrell, M. Fitzmaurice, M. $\mathrm{S}$. Feld, Laser induced fluorescence spectroscopy of normal and atherosclerotic human aorta using 306-310 nm excitation, Lasers in Surgery and Medicine 10 (1990), pp. 245-261. DOI: $10.1002 / 1 \mathrm{sm} .1900100305$

[15] H. Itagaki, T. Tanaka, Experimental Methods in Polymer Science. Modern Methods in Polymer Research and Technology, Polymers, Interfaces and Biomaterials, Academic Press, Boston, 2000, ISBN 978-0-08-050612-8, pp. 155-260.

[16] G. Bitossi, R. Giorgi, M. Mauro, B. Salvadori, L. Dei, Spectroscopic techniques in cultural heritage conservation: a survey, Applied Spectroscopy Reviews 40(3) (2005), pp.187-228. DOI: $10.1081 /$ ASR-200054370

[17] E. R. de la Rie, Fluorescence of paint and varnish layers (parts 13), Stud. Conserv. 27 (1982), pp. 1-7, 65-69, 102-108. DOI: $10.2307 / 1506145$

[18] D. Anglos, S. Georgiou, C. Fotakis, Lasers in the analysis of cultural heritage materials, Journal of Nano Research 8 (2009), pp 47-60. DOI: $10.4028 / w w w . s c i e n t i f i c . n e t / J N a n o R .8 .47$

[19] C. Fotakis, D. Anglos, V. Zafiropulos, S. Georgiou, V. Tornari, Lasers in the Preservation of Cultural Heritage: Principles and Applications. Series in Optics and Optoelectronics, CRC Press, Abingdon, UK, 2006, ISBN 142001210X, 9781420012101.

[20] P. Vandenabeele, B. Wehling, L. Moens, H. Edwards, M. De Reu, G. Van Hooydonk, Analysis with micro-Raman spectroscopy of natural organic binding media and varnishes used in art, Analytica Chimica Acta 407 (2000), pp. 261-274. DOI: $10.1016 /$ S0003-2670(99)00827-2

[21] M. Marinelli, A. Pasqualucci, M. Romani, G. Verona-Rinati, Time resolved laser induced fluorescence for characterization of binders in contemporary artworks, Journal of Cultural Heritage 23 (2017), pp. $98-105$.

DOI: $10.1016 /$ i.culher.2016.09.005
[22] J. R. Lakowicz, S. Keating-Nakamoto, Red-edge excitation of fluorescence and dynamic properties of proteins and membranes, Biochemistry 23(13) (1984), pp. 3013-3021. DOI: $10.1021 /$ bi00308a026

[23] L. B. McGown, K. Nithipatikom, Molecular fluorescence and phosphorescence, Applied Spectroscopy Reviews 35(4) (2007), pp. 353-393. DOI: $10.1081 /$ ASR-100101229

[24] J. R. Lakowicz, Introduction to Fluorescence. In: Principles of Fluorescence Spectroscopy, Springer, Boston, 1999, ISBN 978-0387-31278-1.

[25] C. Fotakis, D. Anglos, V. Zafiropulos, S. Georgiou, V. Tornari, Lasers in the Preservation of Cultural Heritage: Principles and Applications, 1st edition, CRC Press, Boca Raton, 2006, ISBN 9780367390051.

[26] I. Osticioli, N. F. C. Mendes, A. Nevin, A. Zoppi, C. Lofrumento, M. Becucci, E. M. Castellucci, A new compact instrument for Raman, laser-induced breakdown, and laser-induced fluorescence spectroscopy of works of art and their constituent materials, Review of Scientific Instruments 80(7) (2009) 076109. DOI: $10.1063 / 1.3184102$

[27] F. Colao, R. Fantoni, L. Fiorani, A. Palucci, I. Gomoiu, Compact scanning lidar fluorosensor for investigations of biodegradation on ancient painted surfaces, J. Optoelectron Adv. Mater. 7(6) (2005), pp. 3197-3208

[28] V. Spizzichino, L. Caneve, F. Colao, Stand-off device for plastic debris recognition in post-blast scenarios, Challenges 7(2) (2016) 23, 12 pp. DOI: $10.3390 /$ challe 7020023

[29] A. Nevin, S. Cather, D. Anglos, C. Fotakis, Laser-induced fluorescence analysis of protein-based binding media, in: Lasers in the Conservation of Artworks, Springer Proceedings in Physics 116. J. Nimrichter, W. Kautek, M. Schreiner (editors). Springer, Cham, Switzerland, 2007, ISBN 978-3-540-72130-7, pp. 399-406. DOI: $\underline{10.1007 / 978-3-540-72310-7 \quad 47}$

[30] L. Caneve, V. Spizzichino, E. Antonelli, L. Bertani, Study of ancient Egyptian artefacts by non-destructive laser based techniques, Proc. of IEEE International Conference on Metrology for Archaeology and Cultural Heritage, Cassino, Italy, 22-24 Oct 2018, pp. 379-383.

DOI: $\underline{10.1109 / \text { MetroArchaeo43810.2018.9089811 }}$ 